\title{
Changes in soil organic carbon after more than ten years of continuous organic matter application in orchards in Japan
}

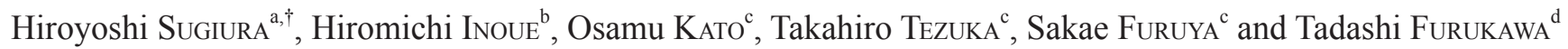 \\ $\left(\begin{array}{l}{ }^{\text {a }} \text { National Agriculture and Food Research Organization, Institute of Fruit Tree Science, 301-2 Akitsuchomitsu, Higashihiroshima, } \\ \text { Hiroshima 739-2494, Japan } \\ { }^{\text {b }} \text { National Agriculture and Food Research Organization, Institute of Fruit Tree Science, 2-1 Fujimoto, Tsukuba, Ibaraki 305-8605, Japan } \\ { }^{\text {c } Y a m a n a s h i ~ F r u i t ~ T r e e ~ E x p e r i m e n t ~ S t a t i o n, ~} 1204 \text { Esohara, Yamanashi, Yamanashi 405-0043, Japan } \\ { }^{\mathrm{d}} \text { Nagasaki Agricultural and Forestry Technical Development Center, } 1370 \text { Onibashimachi, Omura, Nagasaki 856-0021, Japan }\end{array}\right)$
}

\begin{abstract}
To clarify the effect of organic matter application on soil carbon sequestration in orchards, long-term field experiments ( $>10$ years) were conducted at three sites (in Tsukuba, Yamanashi, and Omura) characterized by different fruit crop species, soil types, and climate. Three treatments were established in plots at all sites: (i) clean cultivation (CC, the control), in which chemical fertilizer was applied and the ground was kept bare; (ii) sod culture (SC), in which chemical fertilizer was applied and the ground was covered by grass or weeds; and (iii) organic amendment (OA), in which chemical fertilizer and cattle manure $\left(\mathrm{OA}_{\mathrm{cat}}\right)$ or bark compost $\left(\mathrm{OA}_{\mathrm{brk}}\right)$ were applied and the ground was kept bare. At Tsukuba, annual changes in soil organic carbon concentration $\left(\mathrm{a}_{\mathrm{soc}}\right)$ were lowest in $\mathrm{CC}$ and highest in $\mathrm{OA}_{\text {cat }}$ and $\mathrm{OA}_{\text {brk }}$ plots. At Yamanashi, CC plots lost soil carbon, and $\mathrm{a}_{\mathrm{soc}}$ increased the highest in $\mathrm{OA}_{\text {cat }}$ plots. At Omura, $\mathrm{a}_{\mathrm{soc}}$ was negative in $\mathrm{CC}$ and SC plots and was positive in $\mathrm{OA}_{\mathrm{brk}}$ plots. Within treatments, annual changes in soil organic carbon were highest in OA plots and lowest in CC plots at all sites; positive differences between control and treatment plots indicated that application of organic matter increased soil carbon sequestration.
\end{abstract}

Key words: Long-term field experiment, Orchard, Organic matter application, Soil organic carbon

\section{Introduction}

The estimated global soil organic carbon (SOC) pool is 1550 $\mathrm{Pg} \mathrm{C}$, which is approximately twice that of the atmospheric pool (760 Pg C) and three times that of the biotic pool (560 Pg C) ( $\mathrm{Lal}$, 2004a). Soil plays a critical role in the Earth's carbon cycle as a location for carbon storage. SOC content is governed by the balance between $\mathrm{C}$ inputs and outputs on agricultural lands and is strongly influenced by soil management practices (Lal, 2004b). Recommended strategies for enhancing the ability of agricultural soil to provide a sink for atmospheric carbon dioxide include notill farming, cover crops, and manuring (Lal, 2004a). Orchards (e.g., vineyards, citrus groves) are typically managed using notill, ground cover vegetation (e.g., cover crops, weeds), manure application, or a combination of these practices. Therefore, conditions in orchards are generally more conducive to soil $\mathrm{C}$ storage than conditions in other types of agricultural land, and orchards are considered favorable sites for soil C sequestration (Nakai, 2006).

Many field experiments have been conducted in orchards to elucidate the effects of organic amendments on soil C (e.g., Kato, 2001; Sakamoto et al., 1965; Sekiya et al., 1983). However, the results of those studies are inconclusive because changes in $\mathrm{SOC}$ are related to the initial soil $\mathrm{C}$ levels, and soil responses to organic matter inputs depend on soil type, texture, temperature,

Received; March 29, 2016.

Accepted; November 17, 2016.

†Corresponding Author: hsugiura@affrc.go.jp

DOI: 10.2480/agrmet.D-16-00006 and moisture status (Leon et al., 2015). Moreover, changes in SOC induced by management practices occur slowly, and these changes are relatively small and vary spatially and temporally. For these reasons, long-term field experiments are a preferred approach for understanding changes in SOC.

We previously reported changes in SOC from a long-term field experiment conducted in a vineyard using various fertilization methods and soil surface management practices (Inoue et al., 2012). In that study, the quantity of SOC differed greatly between the treatments; in treatments with a grass cover crop or application of manure and compost, SOC increased quickly in the first decade but increased little in the second decade (Inoue et al., 2012). However, our previous study was performed at a single site, so the influence of local climate and soil characteristics might limit the generalizability of our findings. Uncertainty remains about which management methods enhance soil $\mathrm{C}$ sequestration. Here, to clarify the effects of organic matter application on soil C sequestration, we investigated long-term changes ( $>10$ years) in SOC in a field experiment using the same treatments at three sites that differed in fruit crop species, soil texture, and climate.

\section{Materials and Methods}

\subsection{Experimental design}

This long-term field experiment was conducted in orchards at Tsukuba, Yamanashi, and Omura (Table 1). We established three types of plots with different fertilization methods and soil surface management: (i) clean cultivation (CC, the control), in which chemical fertilizer was applied and the ground was kept bare; (ii) sod culture (SC), in which chemical fertilizer was applied 
Table 1. Characteristics of the study sites.

\begin{tabular}{cccccccc}
\hline Site $^{\text {a }}$ & Crop species & $\begin{array}{c}\text { Latitude } \\
\left({ }^{\circ} \mathrm{N}\right)\end{array}$ & $\begin{array}{c}\text { Longitude } \\
\left({ }^{\circ} \mathrm{E}\right)\end{array}$ & $\begin{array}{c}\text { Elevation } \\
(\mathrm{m} \text { a.s.l. })\end{array}$ & $\begin{array}{c}\text { Air temperature } \\
\left({ }^{\circ} \mathrm{C}\right)\end{array}$ & $\begin{array}{c}\text { Precipitation } \\
(\mathrm{mm})\end{array}$ & Soil type \\
\hline TKB & Grape & 36.05 & 140.01 & 25 & $13.4^{\mathrm{b}}$ & $1270^{\mathrm{b}}$ & Andosol \\
YMN & Peach & 35.70 & 138.66 & 430 & $14.1^{\mathrm{c}}$ & $1131^{\mathrm{c}}$ & Brown Lowland soil \\
OMR & Citrus & 32.95 & 129.96 & 60 & $17.0^{\mathrm{d}}$ & $1837^{\mathrm{d}}$ & Yellow soil \\
\hline
\end{tabular}

${ }^{\text {a }}$ Site names: TKB, Tsukuba; YMN, Yamanashi; OMR, Omura.

${ }^{\mathrm{b}}$ Annual mean air temperature and total precipitation $(1983$ - 1994) from the Automated Meteorological Data Acquisition System (AMeDAS), Tsukuba.

c Annual mean air temperature and total precipitation (1997 - 2008) from AMeDAS, Katsunuma.

${ }^{\mathrm{d}}$ Annual mean air temperature and total precipitation (1986 - 1996) from AMeDAS, Nagasaki.

and the ground was covered by grass or weeds; and (iii) organic amendment (OA), in which chemical fertilizer and cattle manure $\left(\mathrm{OA}_{\mathrm{cat}}\right)$ or bark compost $\left(\mathrm{OA}_{\mathrm{brk}}\right)$ were applied and the ground was kept bare. Herbicides were used to keep the soil surface bare in the $\mathrm{CC}$ and OA plots. In the SC plots, the cover plants were mown to the ground level at least three times per year, and the cut material was left on the soil surface. Harvested fruit and pruned branches were removed from all plots, and fallen material from crop plants (e.g., flowers, leaves) was left in the plots.

\subsection{Tsukuba site}

The Tsukuba site (TKB) was located at the National Agriculture and Food Research Organization, Institute of Fruit Tree Science in Tsukuba, Ibaraki. Grapevines (Vitis labrusca L. 'Campbell Early') were planted at the site in 1979, and all plants were grown using the same management practices. The longterm field experiment started in 1983 and continued until 2010. One 0.3-ha plot was established for each of the four treatments (CC, SC, $\mathrm{OA}_{\text {cat }}$, and $\mathrm{OA}_{\text {brk }}$; see section 2.1). Chemical fertilizer was applied annually at the same rate in all plots: at $100 \mathrm{~kg} \mathrm{~N}$ $\mathrm{ha}^{-1}$ (1983-1987, 1999-2010), $60 \mathrm{~kg} \mathrm{~N} \mathrm{ha}^{-1}$ (1988-1993), and $40 \mathrm{~kg} \mathrm{~N} \mathrm{ha}^{-1}(1994-1998)$. In the SC plots, the ground surface was kept covered by orchardgrass (Dactylis glomerata L.). The cattle manure and bark compost were applied each year from mid-November to early December, with an annual application rate of $30 \mathrm{Mg} \mathrm{ha}^{-1}$ each in the $\mathrm{OA}_{\text {cat }}$, and $\mathrm{OA}_{\text {brk }}$ plots, respectively. After application of amendments, soil in the $\mathrm{CC}$ and OA plots was plowed to $0-10 \mathrm{~cm}$ (shallow plowing). Composite soil samples consisting of four samples per plot at soil depths of $0-20 \mathrm{~cm}$ were taken before fertilization. The soil samples were air dried and sieved through a 2-mm screen. Soil total C was determined by a dry combustion method (SUMIGRAPH NC220F; Sumika Chemical Analysis Service, Osaka, Japan). Soil bulk density $(\rho)$ at $0-20 \mathrm{~cm}$ was measured in 2009 and 2010 . Analysis of soil C was performed from 1983 through 1994, and the $\mathrm{C}$ and nitrogen $(\mathrm{N})$ content of cattle manure and bark compost was analyzed in 2010. Annual aboveground biomass of orchardgrass was measured in 2009, and root biomass was estimated by assuming a ratio of aboveground-to-root biomass (top/ root ratio) of 6.0:1 (Morita et al., 1994).

\subsection{Yamanashi site}

The Yamanashi site (YMN) was located at Yamanashi Fruit Tree Experiment Station in Yamanashi City, Yamanashi Prefecture. Peach trees (Prunus persica L. Batsch 'Hakuhou') were planted at the site in 1997. Long-term field experiments started in 1997 and are still underway. Three treatments were established: $\mathrm{CC}, \mathrm{SC}$, and $\mathrm{OA}_{\text {cat }}$ (see section 2.1). The plot size ranged from 0.06 to 0.09 ha, there were three replicates of each plot type. Chemical fertilizer was applied annually in $\mathrm{CC}$ and $\mathrm{SC}$, and the $\mathrm{N}$ application rate was adjusted over time as follows: $40 \mathrm{~kg} \mathrm{~N} \mathrm{ha}^{-1}$ (1997-1998), $60 \mathrm{~kg} \mathrm{~N} \mathrm{ha}^{-1}(1999-2000)$, $80 \mathrm{~kg} \mathrm{~N}^{-1}$ (2001), $100 \mathrm{~kg} \mathrm{~N}^{-1}(2002-2004)$, and $120 \mathrm{~kg}$ $\mathrm{N}^{-1}(2005-2015)$. The $\mathrm{N}$ application rate in $\mathrm{OA}_{\text {cat }}$ was $0.4 \mathrm{~kg}$ $\mathrm{N} \mathrm{ha}{ }^{-1}(1999-2000), 0 \mathrm{~kg} \mathrm{~N}$ ha $^{-1}(2001-2004)$, and $20 \mathrm{~kg}$ $\mathrm{N} \mathrm{ha}^{-1}(2005-2015)$. In the SC plots, the orchard soil surface was kept under weed-free ground cover (e.g., annual bluegrass, barnyardgrass, southern crabgrass). In the cattle manure treatment, manure was applied each year from mid-November to early December at $20 \mathrm{Mg} \mathrm{ha}^{-1}$ (1997-1998), $35 \mathrm{Mg} \mathrm{ha}^{-1}$ (1999 -2001), and $40 \mathrm{Mg} \mathrm{ha}^{-1}(2002-2015)$. The CC and $\mathrm{OA}_{\text {cat }}$ plots were plowed to $20 \mathrm{~cm}$ every 4 or 5 years. Composite soil samples consisting of three samples per plot at soil depths of $0-20 \mathrm{~cm}$ were taken before fertilization. The soil samples were air dried and sieved through a 2-mm screen. Soil total $\mathrm{C}$ was determined by a dry combustion method (CHN-2400; Perkin Elmer, Waltham, MA, USA). Bulk density at $0-20 \mathrm{~cm}$ was measured in 2009 . Soil $\mathrm{C}$ analysis was performed for 11 years (1997 to 2008). Manure was analyzed for C and N annually from 2009 through 2014. Annual aboveground biomass of the cover vegetation was measured from 2009 through 2014, and root biomass was estimated by assuming a top/root ratio of 2.4:1 (Sekikawa et al., 2003a).

\subsection{Omura site}

The Omura site (OMR) was located at Nagasaki Fruit Tree Experiment Station in Omura, Nagasaki. Iyo tangor (Citrus iyo hort. ex Tanaka 'Miyauchi') was planted at the site in 1983. Long-term field experiments were started in 1986 with three treatments $\left(\mathrm{CC}, \mathrm{SC}\right.$, and $\mathrm{OA}_{\text {brk }}$; see section 2.1) and continued until 1996. All plots were 0.1 ha and there were three sub-plots of each plot type. Chemical fertilizer was applied annually, but the $\mathrm{N}$ fertilization rate differed for each of the three treatment sub-plots; one sub-plot received the standard amount specified for fruit cultivation by Nagasaki Prefecture (Nagasaki Fruit Tree Experiment Station, 1997), one sub-plot received half of this standard amount, and one received twice this standard amount. In each standard sub-plot, the $\mathrm{N}$ fertilization rate was gradually increased from $50 \mathrm{~kg} \mathrm{~N} \mathrm{ha}^{-1}$ in the first year (1986) to $270 \mathrm{~kg} \mathrm{~N}$ $\mathrm{ha}^{-1}$ in the eighth year and until the end of the experiment (1996). In SC plots, the orchard soil surface was maintained under weed-free ground cover (e.g., purple nutsedge, hairy fleabane, sild celery). Bark compost was applied each year in December at a rate of $30 \mathrm{Mg} \mathrm{ha}^{-1}$. Composite soil samples consisting of 

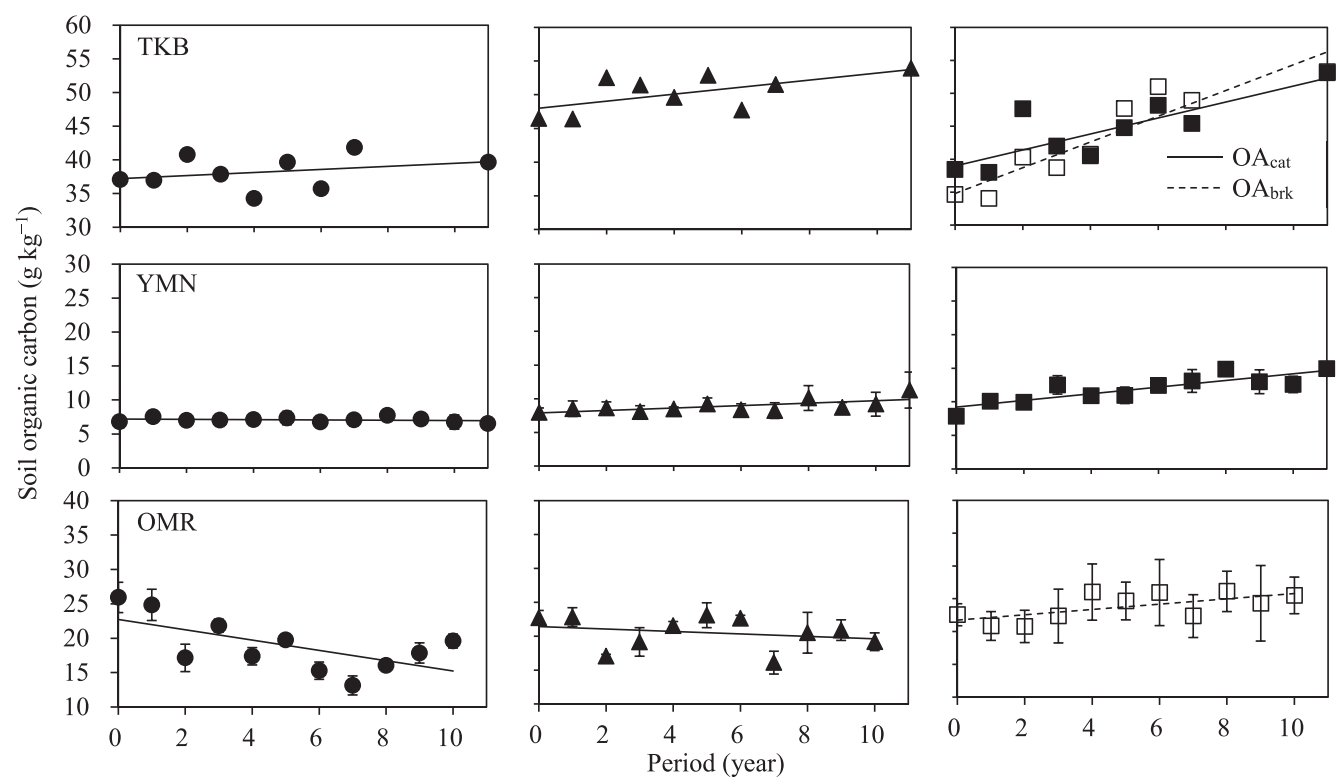

Fig. 1. Changes in the concentration of soil organic carbon in orchards over one decade, as influenced by different management practices. Symbols: $(\mathbf{O})$, clean cultivation (control); $(\boldsymbol{\Lambda})$, sod culture (ground cover vegetation); $(\mathbf{\square})$, cattle manure application; $(\square)$, bark compost application. Lines represent linear regressions. Bars represent SE $(n=3)$, except TKB $(n=1)$.

four samples per plot $(0-20 \mathrm{~cm})$ were taken annually before fertilizer application. The soil samples were air dried and sieved through a 2-mm screen. Soil total $\mathrm{C}$ was determined by a dry combustion method (SUMIGRAPH NC-220F). Analysis of soil C was performed from 1986 through 1996. Bulk density was not measured during the long-term field experiment but was sampled at $0-20 \mathrm{~cm} 17$ years after the end of the experiment (in 2013). Satsuma mandarin (Citrus unshiu Marc. 'Sasebounshu') had been planted in the same plots after the end of the long-term field experiment and was being cultivated conventionally. The $\mathrm{C}$ and $\mathrm{N}$ content of bark compost was estimated from compositional data provided by the supplier. Annual aboveground biomass of the cover vegetation was measured in 1986, and root biomass was estimated by assuming a top/root ratio of 1.4:1 (Nagasaki Fruit Tree Experiment Station, 1997).

\subsection{Soil $\mathrm{C}$ sequestration analysis}

The soils contained little inorganic $\mathrm{C}$, and we assumed that the total soil $\mathrm{C}$ concentration was equivalent to the SOC concentration. Temporal trends in SOC concentration (slope of the linear regression between SOC and year; $\mathrm{g} \mathrm{kg}^{-1} \mathrm{y}^{-1}$ ), Pearson correlation coefficients $(r)$, and the $p$ values of $r$ were analyzed with JMP ver. 9 (SAS Institute, Cary, NC, USA). Results with $p$ values $<0.05$ were considered statistically significant. Annual changes in SOC $\left(\mathrm{Mg} \mathrm{ha}^{-1} \mathrm{y}^{-1}, 0-20 \mathrm{~cm}\right.$ soil depth) were calculated by multiplying temporal trends (annual changes) in SOC concentration $\left(\mathrm{a}_{\mathrm{soc}}\right)$ by $\rho$. We assumed that $\rho$ would not change during the experimental period. Annual rates of soil $\mathrm{C}$ sequestration due to addition of organic matter (ground cover vegetation in SC plots and cattle manure or bark compost in OA plots) were determined by subtracting the annual change in SOC in control plots from that in treatment plots. We assumed that root of ground cover vegetation died in winter and that the entire plant body (the cut tops and roots) were added to the soil. The amount of organic matter remaining undecomposed each year (annual survival rate)
Table 2. Slope $\left(\mathrm{a}_{\mathrm{soc}}\right)$, regression coefficient $(r)$, and $p$ values for linear regressions of changes in SOC concentrations versus time in long-term field experiments with and without addition of organic matter.

\begin{tabular}{ccccc}
\hline Site & Plot $^{\mathrm{a}}$ & $\begin{array}{c}\mathrm{a}_{\text {soc }} \\
\left(\mathrm{g} \mathrm{kg}^{-1} \mathrm{y}^{-1}\right)\end{array}$ & $r$ & $p$ value \\
\hline \multirow{4}{*}{$\mathrm{TKB}$} & $\mathrm{CC}$ & 0.23 & 0.10 & 0.41 \\
& $\mathrm{SC}$ & 0.52 & 0.39 & 0.07 \\
& $\mathrm{OA}_{\text {cat }}$ & 1.21 & 0.68 & $<0.01$ \\
& $\mathrm{OA}_{\text {brk }}$ & 1.95 & 0.86 & $<0.01$ \\
\hline \multirow{4}{*}{$\mathrm{YMN}$} & $\mathrm{CC}$ & -0.02 & -0.05 & 0.48 \\
& $\mathrm{SC}$ & 0.18 & 0.47 & 0.01 \\
& $\mathrm{OA}_{\text {cat }}$ & 0.50 & 0.86 & $<0.01$ \\
\hline \multirow{3}{*}{$\mathrm{OMR}$} & $\mathrm{CC}$ & -0.75 & -0.63 & 0.04 \\
& $\mathrm{SC}$ & -0.18 & -0.25 & 0.46 \\
& $\mathrm{OA}_{\text {brk }}$ & 0.40 & 0.65 & 0.03 \\
\hline
\end{tabular}

${ }^{a}$ Treatment plots: CC, clean cultivation (control); SC, sod culture (ground cover vegetation); $\mathrm{OA}_{\text {cat }}$, cattle manure application; $\mathrm{OA}_{\text {brk }}$, bark compost application.

was calculated by dividing annual soil $\mathrm{C}$ sequestration by the annual amount of organic matter added.

\section{Results}

The three treatments had varying effects on SOC concentration at each study site (Fig. 1, Table 2). At TKB, the regression coefficient $(r)$ was positive for all plots, and the slope of the change in SOC concentration over time $\left(\mathrm{a}_{\mathrm{soc}}\right)$ increased in the order of $\mathrm{CC}<\mathrm{SC}<\mathrm{OA}_{\text {cat }}<\mathrm{OA}_{\mathrm{brk}}$; the regressions were not significant for $\mathrm{CC}$ or $\mathrm{SC}$ plots but were highly significant for $\mathrm{OA}_{\text {cat }}$ and $\mathrm{OA}_{\text {brk }}$ plots $(p<0.01)$. At YMN, SOC concentration did not significantly change in the $\mathrm{CC}$ plot, but the regressions were highly significant for $\mathrm{SC}$ and $\mathrm{OA}_{\text {cat }}$ ( $p<0.05$ and $p<0.01$, respectively), 
H. Sugiura et al. : SOC changes after more than ten years of continuous organic matter application in orchards in Japan

Table 3. Bulk density and SOC dynamics in orchard soils in long-term field experiments.

\begin{tabular}{|c|c|c|c|c|c|c|}
\hline Site & Plot & $\begin{array}{l}\text { Soil bulk density } \\
\qquad\left(\mathrm{Mg} \mathrm{m}^{-3}\right)\end{array}$ & $\begin{array}{c}\text { Annual SOC change }{ }^{\mathrm{a}} \\
\left(\mathrm{Mg} \mathrm{C} \mathrm{ha}^{-1} \mathrm{y}^{-1}\right)\end{array}$ & $\begin{array}{c}\Delta \mathrm{SOC}^{\mathrm{b}} \\
\left(\mathrm{Mg} \mathrm{C} \mathrm{ha}^{-1} \mathrm{y}^{-1}\right)\end{array}$ & $\begin{array}{l}\text { Organic matter } \\
\left(\mathrm{Mg} \mathrm{C} \mathrm{ha}^{-1} \mathrm{y}^{-1}\right)\end{array}$ & $\begin{array}{c}\text { C survival rate } \\
(\%)\end{array}$ \\
\hline \multirow{4}{*}{ TKB } & $\mathrm{CC}$ & 0.80 & 0.37 & - & - & - \\
\hline & $\mathrm{SC}$ & 0.69 & 0.72 & 0.35 & 4.32 & 8.1 \\
\hline & $\mathrm{OA}_{\text {cat }}$ & 0.76 & 1.84 & 1.47 & 4.00 & 36.8 \\
\hline & $\mathrm{OA}_{\mathrm{brk}}$ & 0.78 & 3.04 & 2.67 & 4.80 & 55.7 \\
\hline \multirow{3}{*}{ YMN } & $\mathrm{CC}$ & 1.47 & -0.06 & - & - & - \\
\hline & SC & 1.47 & 0.53 & 0.59 & 2.98 & 19.8 \\
\hline & $\mathrm{OA}_{\text {cat }}$ & 1.41 & 1.41 & 1.47 & $5.84^{\mathrm{e}}$ & 25.2 \\
\hline \multirow{3}{*}{ OMR } & $\mathrm{CC}$ & & -1.71 & - & - & - \\
\hline & SC & $1.14^{\mathrm{f}}$ & -0.41 & 1.30 & 2.16 & 59.9 \\
\hline & $\mathrm{OA}_{\mathrm{brk}}$ & & 0.92 & 2.63 & 4.40 & 59.8 \\
\hline
\end{tabular}

${ }^{\mathrm{a}}$ The annual change in SOC $(0-20 \mathrm{~cm}$ soil depth) was calculated by multiplying the annual change in SOC concentration by soil bulk density.

${ }^{\mathrm{b}} \triangle \mathrm{SOC}$, soil $\mathrm{C}$ sequestration resulting from organic matter addition, was calculated by subtracting the change in SOC in control plots $(\mathrm{CC})$ from that in treatment plots.

${ }^{c}$ Organic matter, the amount of organic matter added (ground cover vegetation in SC plots and cattle manure or bark compost in OA plots).

${ }^{\mathrm{d}} \mathrm{C}$ survival rate (the percentage of applied organic material remaining undecomposed in the soil at the end of the experiment) was calculated by dividing soil $\mathrm{C}$ sequestration by the quantity of organic matter applied.

${ }^{\mathrm{e}}$ Average $\mathrm{OA}_{\text {cat }}$ for 11 years.

${ }^{\mathrm{f}}$ Average soil bulk density in $\mathrm{CC}, \mathrm{SC}$ and $\mathrm{OA}_{\text {brk }}$ plots 17 years after the end of the long-term field experiment.

with the most rapid SOC increase observed in $\mathrm{OA}_{\text {cat }}$. At OMR, average SOC concentration was obtained from three subplots per treatment; average SOC decreased significantly in CC $(p<$ $0.05)$ and tended to decrease in $\mathrm{SC}$, and increased significantly in $\mathrm{OA}_{\text {brk }}(p<0.05)$.

At TKB, soil bulk density $(\rho)$ was approximately the same in all the plots without grass cover $\left(0.76-0.80 \mathrm{Mg} \mathrm{m}^{-3}\right)$, and was lower in SC plots $\left(0.69 \mathrm{Mg} \mathrm{m}^{-3}\right)$. At YMN, $\rho$ did not differ among the plots $\left(1.41-1.47 \mathrm{Mg} \mathrm{m}^{-3}\right)$. At OMR, we assumed that $\rho$ was the same in all plots $\left(1.14 \mathrm{Mg} \mathrm{m}^{-3}\right)$ (Table 3 ).

The C:N ratios of manure or compost were 16.3 in $\mathrm{OA}_{\text {cat }}$ and 25.2 in $\mathrm{OA}_{\text {brk }}$ at TKB, 15.8 in $\mathrm{OA}_{\text {cat }}$ at $\mathrm{YMN}$, and 35.0 in $\mathrm{OA}_{\text {brk }}$ at $\mathrm{OMR}$.

Annual changes in SOC in a given plot type differed among the study sites, but at all sites, changes in SOC were lowest in the control and highest in OA plots. The differences in annual changes in SOC between control and treatment plots $(\triangle \mathrm{SOC})$ were positive at all sites (Table 3 ).

The quantity of organic matter added by ground cover vegetation, manure, and compost varied between approximately 2.2 and $5.8 \mathrm{Mg} \mathrm{Cha}^{-1} \mathrm{y}^{-1}$. At the end of the experiment, $8 \%-60 \%$ of added organic matter remained in the soil in the SC treatment, $25 \%-37 \%$ remained in $\mathrm{OA}_{\text {cat }}$ plots, and $56 \%-60 \%$ remained in $\mathrm{OA}_{\text {brk }}$ plots (Table 3).

\section{Discussion}

\subsection{Effects of treatments on SOC concentration}

The long-term field experiments performed in three different orchards showed significant linear regressions in the change of SOC concentration over time, except for in the CC plots at TKB and YMN and the SC plot at TKB and OMR (Fig. 1, Table 2). Although the dynamics of organic matter decomposition in soil are complex, changes in SOC reflect differences in the type of organic matter added and in rates of in situ decomposition (e.g., Inoko, 1981). Changes in SOC can be determined by using a relatively simple numerical model based on reaction kinetics (e.g.,
Jenkinson, 1990) and the shape of a sigmoid curve. However, in our previous $>25$-year study in a vineyard, we concluded that most changes in SOC occur within approximately 10 years, after which additional changes are small (Inoue et al., 2012). In a summary paper, Lal (2004a) also showed that the rate of increase in SOC through land-use change and adoption of recommended management practices (RMPs) follows a sigmoid curve and reaches a maximum 5 to 20 years after adoption of RMPs, and then continues until SOC attains another equilibrium state. The changes in SOC concentration in this 10-year field experiment could be characterized by a linear regression, indicating that this study ended before SOC reached equilibrium. However, there was no clear change in SOC concentration in the CC plots at TKB and YMN and in the SC plot at OMR. SOC concentration in these plots might have reached equilibrium under our study conditions.

SOC decomposition is sensitive to temperature and moisture in the soil (Jenkinson, 1990). SOC decomposition rates have been found to be faster at thermic temperatures than mesic temperatures (Leon et al., 2015). OMR is warmer and has higher precipitation than TKB and YMN (Table 1); therefore, SOC decomposition is expected to be higher at OMR than at TKB or YMN. SOC concentration in the CC plots at OMR decreased rapidly compared to the change in SOC concentration in the $\mathrm{CC}$ plots at TKB and YMN.

Ground cover vegetation can increase SOC concentrations in orchards (e.g., Sakamoto et al., 1965; Shibukawa, 1962). There was an annual increase in SOC in SC plots at TKB and YMN but not at OMR (Fig. 1, Table 2). However, the annual change in SOC was higher in SC plots than in CC plots at all sites, consistent with the findings of Sakamoto et al. (1965).

Our results at TKB (Fig. 1, Table 2) showed a significant increase in SOC concentrations in Andosols in plots amended with cattle manure, but not in CC plots. Sekiya et al. (1983) reported similar findings (also in Andosols) in a 4-year study in which cattle manure $\left(30 \mathrm{Mg} \mathrm{ha}^{-1}\right)$ was applied in orange groves in 
Kanagawa. Kato (2001) applied manure at $15 \mathrm{Mg} \mathrm{ha}^{-1}$ to Brown Lowland soil in an apple orchard in Aomori, northern Japan, for 9 years. In that study, SOC concentrations did not change significantly in control plots but increased significantly in plots that received manure, similar to our results at YMN in Brown Lowland soil. Generally, bark compost is less readily biodegradable than is cattle manure (Taniyama, 2008); this may explain the greater increase in SOC concentration at TKB after application of bark compost, compared to application of manure. All tested organic amendments increased SOC concentration relative to control plots (Fig. 1, Table 2).

\subsection{Soil $\mathrm{C}$ sequestration with organic matter addition}

The supply of carbon to soil from fruit crops, mainly from leaf litter and loss of fine roots, is reported as $1.36 \mathrm{Mg} \mathrm{C}^{-1}$ $\mathrm{y}^{-1}$ for grapes (Sekikawa et al., 2003a), $2.56 \mathrm{Mg} \mathrm{C} \mathrm{ha}^{-1} \mathrm{y}^{-1}$ for peaches (Sekikawa et al., 2003b), and $1.62 \mathrm{Mg} \mathrm{C} \mathrm{ha}^{-1} \mathrm{y}^{-1}$ for Satsuma mandarins (a citrus species, like Iyo tangor) (Fumimuro, 2011). From our results in CC plots, the amount of $C$ supplied by fruit crops is not sufficient to increase SOC (Table 3 ). We assumed that the quantity of $\mathrm{C}$ supplied to soil from the crops did not differ between plots, and we interpreted the annual increase in SOC in treatment plots relative to $\mathrm{CC}$ plots as indicating that the treatment increased soil $\mathrm{C}$ sequestration. All treatment plots had greater increases in SOC than CC plots (Table 3); therefore, the applied organic matter enhanced soil $\mathrm{C}$ sequestration. The contribution of the organic additions to soil $\mathrm{C}$ sequestration was highest for bark compost and lowest for sod culture.

Because fresh grass and weeds are readily biodegradable, plant detritus left on the soil surface after mowing is easily decomposed (Kato, 2001). Except for at the OMR site, the amount of ground cover vegetation remaining on the soil surface was less than the amount of the manure or bark compost (Table 3). The reason for the greater amount of ground cover vegetation remaining at OMR is not clear, but aboveground biomass was quantified only one time at that site, so that result is not conclusive. The amount of bark compost remaining undecomposed was greater than that of cattle manure (Table 3 ). The $\mathrm{C}: \mathrm{N}$ ratio is higher in bark compost than in cattle manure, making bark compost a less readily biodegradable substrate (Taniyama, 2008).

Lal (2004a) summarized observed rates of soil C sequestration in agricultural and restored ecosystems and reported a range of 0 to $0.15 \mathrm{Mg} \mathrm{Cha}^{-1} \mathrm{y}^{-1}$ in warm dry regions and of 0.1 to $1.0 \mathrm{Mg}$ $\mathrm{C} \mathrm{ha}{ }^{-1} \mathrm{y}^{-1}$ in cool humid climates; we observed greater rates of soil $\mathrm{C}$ sequestration in orchards where organic matter was added, especially in plots that received cattle manure or bark compost. The organic amendment rates used in this study were based on management practices recommended by public institutions and might be greater than quantities used in conventional practice. Considering this, orchard soils to which organic matter is applied can sequester increasing amounts of carbon for at least 10 years regardless of fruit crop species, soil type, and climate.

\section{Acknowledgments}

We thank Dr. Shirato of National Institute for AgroEnvironmental Sciences for his kind support of this study. This study was funded in part by the Ministry of Agriculture, Forestry and Fisheries, Japan through a research project
entitled'Development of Technologies for Mitigation and Adaptation to Climate Change in Agriculture, Forestry and Fisheries' (FY 2010 - 2014).

\section{References}

Fumimuro M, 2011: Characteristics of dry matter production and assimilate partitioning in mature Satsuma mandarin trees (Citrus unshiu Marcow.), and effects of sheet mulching and trunk girdling on their characteristics. Horticultural Research 10, 359-366. (in Japanese with English summary)

Inoko A, 1981: Turnover of organic matter in soil -On mathematical approach-. Japanese Journal of Soil Science and Plant Nutrition 52, 548-558. (in Japanese)

Inoue H, Umemiya Y, Kusaba S, Sugiura, H, 2012: Changes in total soil carbon and total soil nitrogen in a long-term vineyard experiment with organic matter. Japanese Journal of Soil Science and Plant Nutrition 83, 687-690. (in Japanese)

Jenkinson DS, 1990: The Turnover of organic carbon and nitrogen in soil. Philosophical Transactions: Biological Sciences 329, 361-368.

Kato T, 2001: Studies on soil management for apple tree on dwarfing rootstocks. Bulletin of the Aomori Apple Experiment Station 32, 1-94. (in Japanese with English summary)

Lal R, 2004a: Soil carbon sequestration impacts on global climate change and food security. Science 304, 1623-1627.

Lal R, 2004b: Soil carbon sequestration to mitigate climate change. Geoderma 123, 1-22.

Leon A, Kohyama K, Takata T, Yagi K, Umemiya Y, Ohkura T, Obara H, 2015: Change in soil carbon in response to organic amendments in orchards and tea gardens in Japan. Geoderma 237-238, 168-175.

Morita O, Goto M, Ehara H, 1994: Growth and dry matter production of pasture plants grown under reduced light conditions of summer season. The bulletin of the Faculty of Bioresources, Mie University 12, 11-20. (in Japanese with English summary)

Nagasaki Fruit Tree Experiment Station 1997: Examination about the establishment of the rational fertilization method of the citrus fruit in the Kyushu area. Nagasaki Fruit Tree Experiment Station, Omura, pp.92. (in Japanese)

Nakai M, 2006: The present situation and issues of the arable lands soil survey. Journal of the Agricultural Society of Japan 1487, 31-51. (in Japanese)

Sakamoto T, Okuchi S, Maruki T, Funagami K, 1965: Ten-year comparison of different soil managements in Satsuma orange orchard. Journal of the Japanese Society for Horticultural Science 34, 277-285. (in Japanese with English summary)

Sekikawa S, Kibe T, Koizumi H, Mariko S, 2003a: Soil carbon budget in peach orchard ecosystem in Japan. Environmental Science 16, 97-104.

Sekikawa S, Kibe T, Koizumi H, Mariko S, 2003b: Soil carbon sequestration in a grape orchard ecosystem in Japan. Journal of the Japanese Agricultural Systems Society 19, 141-150.

Sekiya K, Umemiya Y, Koto M, Hirobe M, 1983: Experiments of cattle faeces application at the Satsuma mandarin orchards of Ando soils. Bulletin of the Fruit Tree Research Station A 10, 73-90. (in Japanese with English summary)

Shibukawa J, 1962: Studies on sod culture as soil management for the apple orchard. Bulletin of the Aomori Apple Experiment Station 5, 1-100. (in Japanese)

Taniyama I, 2008: Carbon sequestration in the agricultural soils of Japan. Pedologist 52, 66-72. (in Japanese) 